\title{
STABILITy ENHANCEMENT OF POWER System USING TYPE-2 FuZzY LOGIC POWER SYSTEM STABILIZER
}

\author{
K.R.Sudha ${ }^{1}$ and I.E.S.Naidu ${ }^{2}$ \\ ${ }^{1}$ Professor, Electrical Engineering Department, Andhra university \\ ${ }^{2}$ Research Scholar, Electrical Engineering Department, Andhra university
}

\begin{abstract}
Power system stabilization is a major issue in the area of power systems research. The Conventional Power System Stabilizer (CPSS) parameters are tuned by using Genetic Algorithm to achieve proper damping over a wide range of operating conditions. The CPSS lack of robustness over wide range of operating conditions. In this paper type-2 Fuzzy Logic Power System Stabilizer (FLPSS) is presented to improve the damping of power system oscillations. To accomplish the best damping characteristics three signals are chosen as in put to FLPSS. Deviation in speed ( $\Delta \omega)$, deviation of speed derivative $(\Delta \vec{\omega})$ and deviation of power angle $(\Delta \delta)$ are taken as input to fuzzy logic controller. The proposed controller is implemented for Single Machine Infinite Bus (SMIB) power system model. The efficacy of the proposed controller is tested over a wide range of operating conditions. The comparison between CPSS, Type-1 FLPSS and Type-2 FLPSS is presented. The results validate the effective ness of proposed Type-2 FLPSS controller in terms of less over/under shoot, settling time and enhancing stability over wide range of generator load variations.
\end{abstract}

\section{KEYWORDS}

Power System Stabilizers, Eigen values, Type-1and Type-2 Fuzzy Logic Control System

\section{INTRODUCTION}

Power system is a typical multi-variable, nonlinear and dynamical system consisting of synchronous alternators, transmission lines, transformers, switching relays and compensators. For keeping the terminal voltage magnitude of synchronous generator within limits, the automatic voltage regulators (AVRs) are adopted in generator excitation system. AVRs introduce negative damping torques, because of which the stability is adversely affected [1]. The power system exhibits electromechanical oscillations because of load variation. These oscillations should be damped to acceptable limitation failing which may result in instability. These oscillations can be damped by using Power System Stabilizers. PSSs generate supplementary signals to excitations system to suppress these oscillations [2].

The CPSSs are led-lag phase compensators tuned using a linearized model of power system for specific operating points to provide the desired damping characteristics [3-4]. Because of nonlinear characteristics of power systems, CPSS is not capable to adapt large changes in operating conditions [5]. Adaptive power system stabilizers are proposed to deal with the variation of operating conditions [6-7]. The Fuzzy Logic Power System Stabilizer (FLPSS) was

DOI : 10.5121/ijfls.2016.6103 
developed to improve the dynamic stability of power systems under wide range of operating conditions. FLPSS shows better performance in dynamic stability compared with CPSS. The constructed FLPSSs rely on expert knowledge which usually consists of uncertainties to certain degree. Therefore, the corresponding fuzzy membership functions parameters [8-12]. This fuzzy logic is also known as type-1 fuzzy logic.

Although the FLPSS have improved power systems stability, recent research has shown the limitations of Type-1 fuzzy logic theory in considering large uncertainties and unexpected disturbances. In order to overcome these limitations, Type-2 fuzzy logic methods are developed [12-15]. The Type-1 fuzzy logic is further be modified to Type- 2 fuzzy by applying grading to the membership functions which to form Type-2 fuzzy sets. A Type- 2 fuzzy set can be envisaged as a three dimensional set and results in an extra degree of freedom for handling uncertainties [16]. Because of this feature, a robust FLPSS is designed using Type-2 fuzzy logic [17]. The proposed controller is simulated for a SMIB and compared with conventional controller and Type-1 fuzzy controller under various operating conditions [18]. Results show that the Type-2 fuzzy controllers guarantee the robust performance over a wide range of operating conditions.

\section{POWER SYSTEM MODEL}

The power system under study is a single machine connected to an infinite bus through a tie-line. The infinite bus is represented by the thevenin equivalent of a large inter connected power system. The machine is outfitted with a static exciter. The non-linear model of the system is described using following differential equations [1].

$$
\begin{aligned}
& \delta=\omega_{0} \omega \\
& \dot{\omega}=\frac{\left(T_{m}-T_{z}\right)}{M}
\end{aligned}
$$

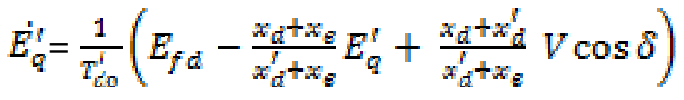

$$
\begin{aligned}
& E_{f d}^{*}=\frac{1}{T_{I}}\left(K_{E} E_{r \theta f}-K_{E} V_{t}-E_{f d}\right)
\end{aligned}
$$

The above equations can be linearized around an operating point for small deviations and is considered from [19].

\subsection{Conventional Power System Stabilizers}

For the system considered to analyze the enhancement of stability margin, the limit cycles are controlled by designing an adaptive lead-lag PSS, whose parameters tuned are $\mathrm{K}, \mathrm{T}_{1}, \mathrm{~T}_{2}$ and Washout time constant, $\mathrm{T}_{\mathrm{w}}$ is considered as 10 seconds. The single stage PSS with Wash-Out is in the form

$$
\begin{aligned}
& U=G_{P S S} \times \Delta \omega \\
& G_{P S S}=\frac{s T_{w}}{1+s T_{w}} \times K \times \frac{1+s T_{1}}{1+s T 2}
\end{aligned}
$$

The parameters of Power System stabilizer (PSS) can be derived from conventional methods or Meta heuristic methods [19-20]. 


\subsection{Type-1 Fuzzy Logic Power System Stabilizer}

The analytical structure of three input three output T1 FLPSS similar to PID Controller is designed heuristically with 27 rules listed in Table 1 [18].

Table 1 : Rules for three input three membership functions

\begin{tabular}{|c|c|c|c|c|c|c|c|c|c|}
\hline Rule & DE & DEE & $\mathbf{E}$ & output & Rule & DE & DEE & $\mathbf{E}$ & output \\
\hline 1 & $\mathrm{P}$ & $\mathrm{P}$ & $\mathrm{P}$ & NB & 14 & $\mathrm{~N}$ & $\mathrm{~N}$ & $\mathrm{~N}$ & PB \\
\hline 2 & $\bar{P}$ & $\mathrm{P}$ & $\mathrm{N}$ & NS & 15 & $\mathrm{~N}$ & $\mathrm{~N}$ & $\bar{Z}$ & PM \\
\hline 3 & $\mathrm{P}$ & $\mathrm{P}$ & $\mathrm{Z}$ & NM & 16 & $\mathrm{~N}$ & $\mathrm{Z}$ & $\mathrm{P}$ & $\mathrm{Z}$ \\
\hline 4 & $\mathrm{P}$ & $\mathrm{N}$ & $\mathrm{P}$ & NM & 17 & $\mathrm{Z}$ & $\mathrm{Z}$ & $\mathrm{Z}$ & PS \\
\hline 5 & $\mathrm{P}$ & $\mathrm{N}$ & $\mathrm{Z}$ & Z & 18 & $\mathrm{Z}$ & Z & $\mathrm{N}$ & PM \\
\hline 6 & $\mathrm{P}$ & $\mathrm{N}$ & $\mathrm{N}$ & NS & 19 & $\mathrm{Z}$ & $\mathrm{P}$ & $\mathrm{P}$ & $\mathrm{NM}$ \\
\hline 7 & $\mathrm{Z}$ & $\mathrm{Z}$ & $\mathrm{P}$ & NM & 20 & $\mathrm{Z}$ & $\mathrm{P}$ & $\mathrm{N}$ & $\mathrm{Z}$ \\
\hline 8 & $\mathrm{~N}$ & $\mathrm{Z}$ & $\mathrm{Z}$ & NS & 21 & $\mathrm{Z}$ & $\mathrm{P}$ & $\mathrm{Z}$ & NS \\
\hline 9 & $\mathrm{~N}$ & $\mathrm{Z}$ & $\mathrm{Z}$ & $\mathrm{Z}$ & 22 & $\mathrm{Z}$ & $\mathrm{N}$ & $\mathrm{P}$ & $\mathrm{ZE}$ \\
\hline 10 & $\mathrm{~N}$ & $\mathrm{P}$ & $\mathrm{P}$ & $\mathrm{NM}$ & 23 & $\mathrm{Z}$ & $\mathrm{N}$ & $\mathrm{N}$ & $\mathrm{PM}$ \\
\hline 11 & $\mathrm{~N}$ & $\mathrm{P}$ & $\mathrm{Z}$ & $\mathrm{Z}$ & 24 & $\mathrm{Z}$ & $\mathrm{N}$ & $\mathrm{Z}$ & PS \\
\hline 12 & $\mathrm{~N}$ & $\mathrm{P}$ & $\mathrm{N}$ & PS & 25 & $\mathrm{Z}$ & $\mathrm{Z}$ & $\mathrm{P}$ & NS \\
\hline 13 & $\mathrm{~N}$ & $\mathrm{~N}$ & $\mathrm{P}$ & PS & 26 & $\mathrm{Z}$ & $\mathrm{Z}$ & $\mathrm{Z}$ & $\mathrm{Z}$ \\
\hline & & 27 & $\mathrm{Z}$ & $\mathrm{Z}$ & $\mathrm{N}$ & $\mathrm{NS}$ & & & \\
\hline
\end{tabular}

In the Type-1 FLPSS controller, the gains are converted to adaptive gains by introducing FLC at the input of the PID Controller. The parameters are tuned by using a systematic approach [18].

\subsection{Type-2 fuzzy logic controllers}

Fuzzy logic system using ordinary fuzzy sets, inference and logic is known as Type-1 fuzzy system [21-22]. A fuzzy logic system using Type-2 fuzzy sets and fuzzy logic and inference is called a Type-2 fuzzy system. A third dimension and footprint of uncertainty is incorporated in Type-2 fuzzy system. Thus, under the state of high uncertainty the type- 2 fuzzy logic controller can perform better than its type-1 counterpart [23]. The type-2 fuzzy logic stabilizer includes a Fuzzifier, a rule base, fuzzy inference engine and an output processor. The block diagram representation of type-2 fuzzy logic controller is shown in Figure1.

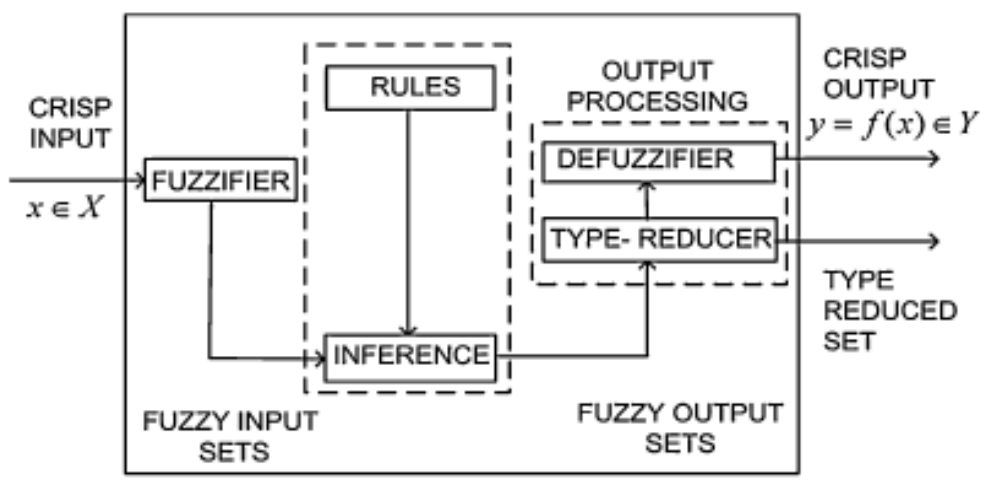

Figure 1 Type-2 Fuzzy Logic System 
The grade of membership of type-1 fuzzy sets is crisp and that of type- 2 fuzzy is fuzzy, hence Type-2 fuzzy sets are 'fuzzy-fuzzy' sets. The membership grade of a type-2 fuzzy logic set is a fuzzy itself [16]. Membership function in interval type-2 fuzzy set can be represented by using as an area called Footprint of Uncertainty (FOU). Working of Type-2 fuzzy is same as the working of Type-1 fuzzy. Type-2 fuzzy is an interval fuzzy system where fuzzy operation is taken as two Type-1 membership functions, Upper Membership Function (UMF) and Lower Membership Function (LMF), to produce the firing strength. This UMF and LMF will limit the FOU. Figure 2 represents Interval type- 2 membership function.

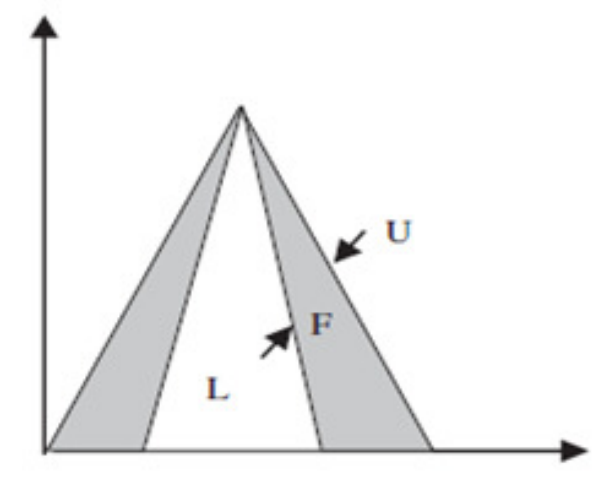

Figure 2. Type-2 interval membership function

A type-2 fuzzy set comprises of two individual membership functions known as primary and secondary. Hence, both primary and secondary membership functions will be in the interval $[0$, 1]. Since, the FOU is designed over an interval, Type-2 fuzzy logic controller can also be referred as interval Type-2 fuzzy logic controller. The effect of considering their FOU over an interval gives the 3-dimensional effect and an extra degree of freedom for handling uncertainties in the Power system stability. The implementation of interval type- 2 membership functions and operators is done by using the IT2FLS toolbox [16].

Type-1 fuzzy system uses ordinary fuzzy sets and inference, whereas type-2 fuzzy system uses type-2 fuzzy sets and inference [14]. Type-1 fuzzy controllers have been developed and applied to practical problems.

Defuzzification is a process of mapping from fuzzy logic control action to a non-fuzzy (crisp) control action using centroid method. Figure 3 describes the process of Defuzzification of interval Type-2 fuzzy system using centroid method. The Inference system uses a fuzzy reasoning mechanism to derive a fuzzy output. 

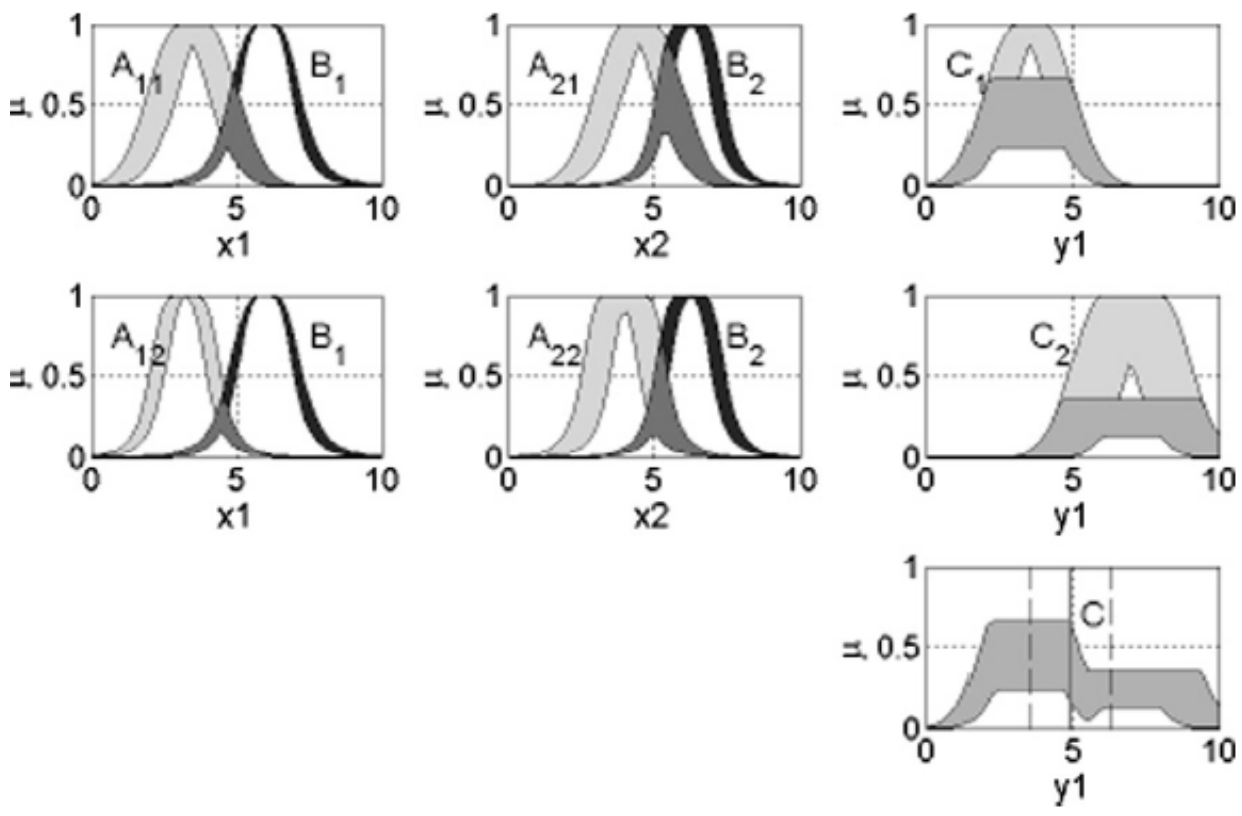

Figure 3 Defuzzification process of an interval Type-2 fuzzy logic system

\subsection{Test System}

The System under study in is a thermal generating station consisting of four 555MVA, 24KV, and $60 \mathrm{~Hz}$ units. The network reactance's are in p.u. on $2220 \mathrm{MVA}, 24 \mathrm{KV}$ base(referred to LT side of step-up transformer). Resistances are assumed to be negligible.

\section{Equivalent generator parameters in p.u:}

$\mathrm{X}_{\mathrm{d}}=1.81, \mathrm{X}_{\mathrm{d}}{ }^{\prime}=0.3, \mathrm{X}_{\mathrm{q}}=1.76, \mathrm{~T}_{\mathrm{do}}{ }^{\prime}=8 \mathrm{sec}, \mathrm{H}=3.5 \mathrm{MJ} / \mathrm{MVA}, \mathrm{Vt}=1.0$

Exciter: $\mathrm{k}_{\mathrm{E}}=25, \mathrm{~T}_{\mathrm{E}}=0.05 \mathrm{Sec}$.

\section{RESULTS AND DISCUSSION}

The design of type-2 FLPSS for damping of oscillations in SMIB test system is presented in this paper. The efficacy of the controller is tested for multiple operating conditions. The results obtained are compared with CPSS and Type-1 FLPSS. Controller Parameters for CPSS and FLPSS are obtained by using Genetic Algorithm. The parameters obtained for CPSS are K= $10.75, \mathrm{~T} 1=0.485$ and $\mathrm{T} 2=0.05$. The gains obtained for FLPSS (FPID) are $\mathrm{kp}=1.01, \mathrm{kd}=20.6837$ and $\mathrm{ki}=0.4676$.

The response in speed deviation of SMIB at light load of $\mathrm{P}+\mathrm{jQ}=0.5+\mathrm{j} 0$ is represented in Figure 4 . The settling time for type-2 FLPSS is $1.307 \mathrm{Sec}$. The settling times obtained with CPSS and type1 FLPSS are $3.036 \mathrm{sec}$ and $1.57 \mathrm{sec}$ respectively. 
International Journal of Fuzzy Logic Systems (IJFLS) Vol.6, No.1, January 2016

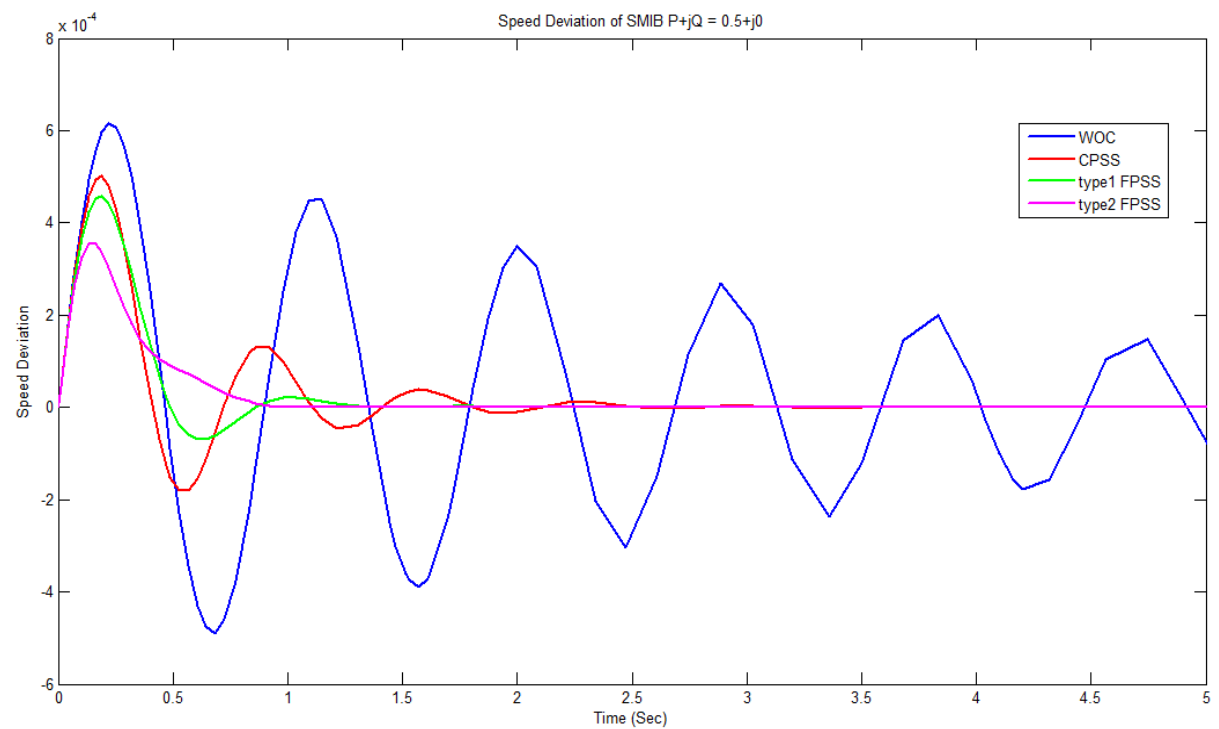

Figure 4 Speed deviation for $\mathrm{P}+\mathrm{jQ}=0.5+\mathrm{j} 0$

The peak overshoot for type-2 FLPSS, type-1 FLPSS and CPSS are $3.54 \times 10^{-4} 4,4.577 \times 10^{-4}$ and $5.024 \times 10^{-4}$ respectively. The peak undershoot for type-2 FLPSS, type-1 FLPSS and CPSS are $9.357 \times 10^{-8}, \quad-6.998 \times 10^{-5}$ and $-1.806 \times 10^{-4}$ respectively. Type-2 FLPSS exhibits lower values of peak overshoot and undershoots compared to type-1 FLPSS and CPSS.

The response in rotor angle deviation of SMIB at light load of $\mathrm{P}+\mathrm{jQ}=0.5+\mathrm{j} 0$ is given in Figure5. Settling time for type-2 FLPSS is 1.09Sec. the settling times obtained with CPSS and type1FLPSS are $2.609 \mathrm{sec}$ and $1.513 \mathrm{sec}$ respectively.

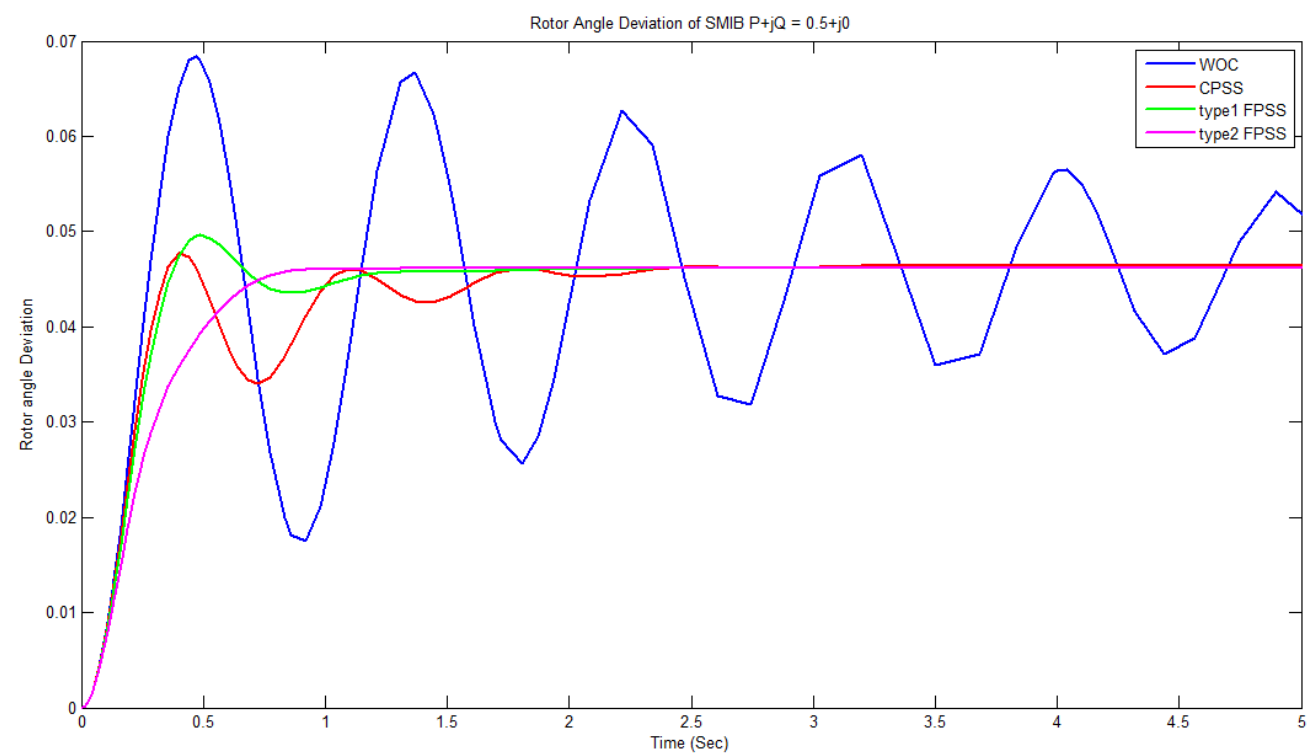

Figure 5 Rotor angle deviation for $\mathrm{P}+\mathrm{jQ}=0.5+\mathrm{j} 0$ 
The peak overshoot for type-2 FLPSS, type-1 FLPSS and CPSS are 0.04607, 0.04953 and 0.04747 respectively. The type-2 FLPSS settles abruptly without any undershoot. The peak undershoot for type-1 FLPSS and CPSS are 0.02894 and 0.02264 respectively. Type-2 FLPSS exhibits lower values peak overshoot compared to type-1 FLPSS and CPSS.

The efficacy of the controller is tested by subjecting the SMIB system to a normal load of $\mathrm{P}+\mathrm{jQ}=1+\mathrm{j} 0$. The response in speed deviation is given in Figure 6. The settling time with type- 2 FLPSS is $1.616 \mathrm{Sec}$ and is relatively less compared to settling times obtained with type-1 FLPSS and CPSS (1.756 and 3.06 respectively).

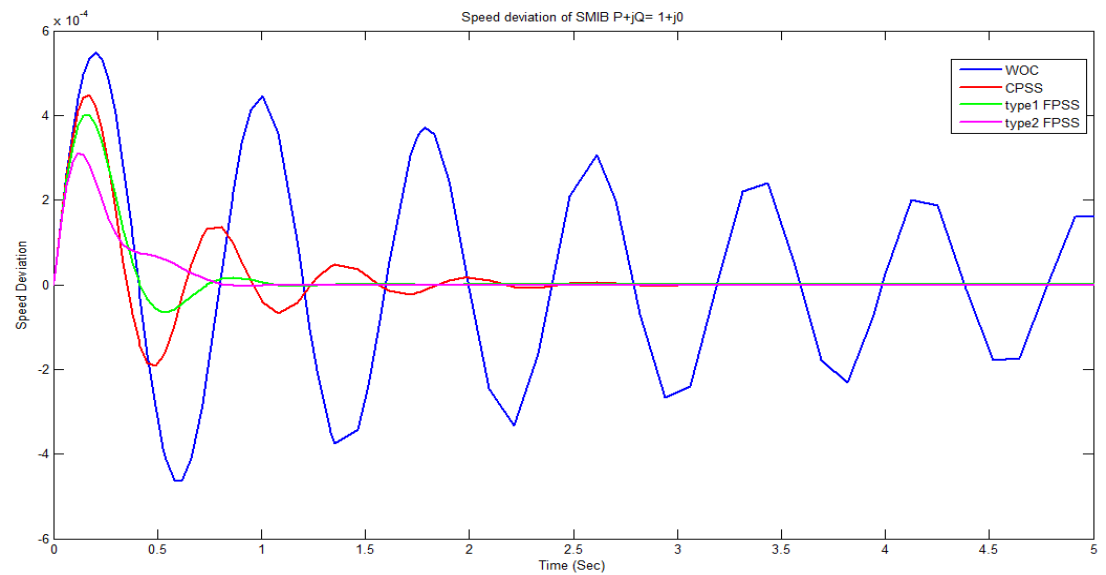

Figure 6 Speed deviation for $\mathrm{P}+\mathrm{jQ}=1+\mathrm{j} 0$

The peak overshoot for type-2 FLPSS, type-1 FLPSS and CPSS are $3.199 \times 10^{-4}, 3.99 \times 10^{-4}$ and $4.477 \times 10^{-4}$ respectively. The peak undershoot for type-2 FLPSS, type-1 FLPSS and CPSS are $2.727 \times 10^{-6}, \quad-6.523 \times 10^{-5}$ and $-1.926 \times 10^{-4}$ respectively. Type-2 FLPSS have lower values of peak overshoot and undershoots compared to type-1 FLPSS and CPSS.

The responses in rotor angle deviation for normal load are given in Figure 7. The settling time with type-2 FLPSS is $1.566 \mathrm{sec}$ and is less compared to the settling time obtained with type-1 FLPSS and CPSS (1.832sec and 2.942sec).

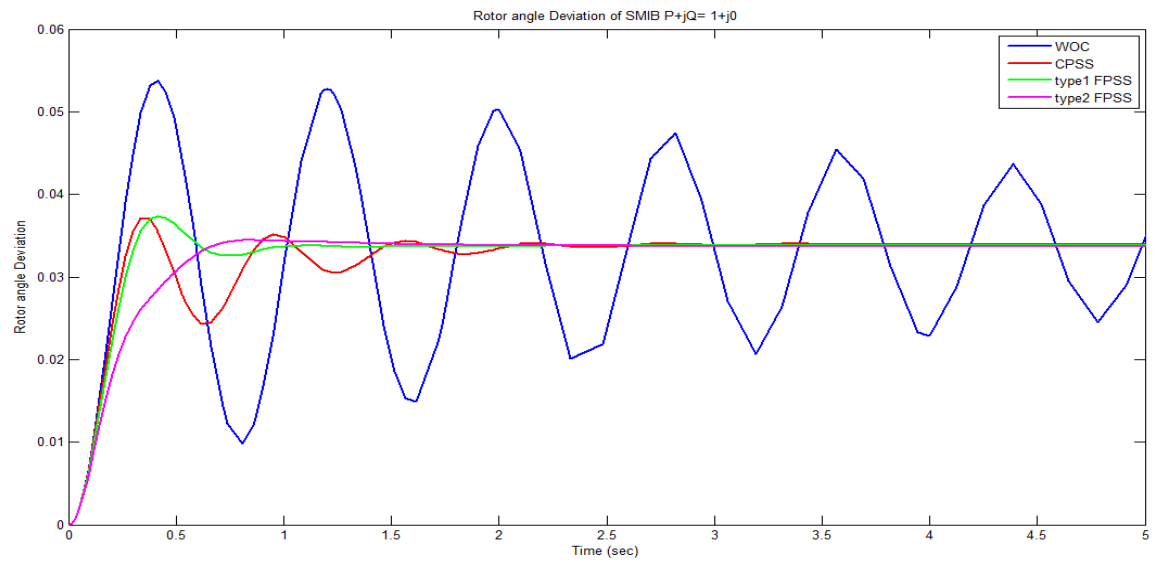

Figure 7 Rotor angle deviation for $\mathrm{P}+\mathrm{jQ}=1+\mathrm{j} 0$ 
The peak over shoots for type-2 FLPSS, type-1 FLPSS and CPSS are 0.03445, 0.03739 and 0.03711 respectively. Type-2 FLPSS settles without any undershoot. The peak under shoot for type- 1 and CPSS are 0.03256 and 0.02434 respectively. Type-2 FLPSS exhibits better response with respect to Settling time, peak overshoot and undershoot compared to type-1 FLPSS and CPSS.

The SMIB is subjected to heavy load of $\mathrm{P}+\mathrm{jQ}=1.5+\mathrm{j} 0.5$. The response in speed deviation and rotor angle deviations are given in Figure 8 and figure 9 respectively. Type-2 FLPSS shows better performance in settling time, peak undershoot and peak overshoot.

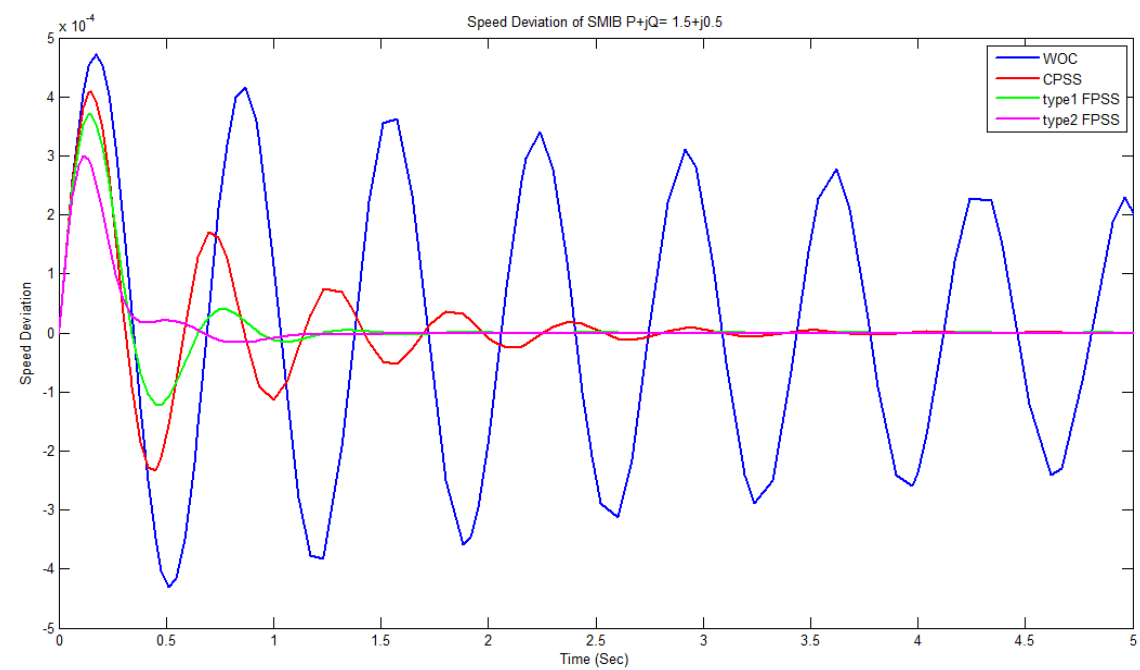

Figure 8 Speed deviation at $\mathrm{P}+\mathrm{jQ}=1.5+\mathrm{j} 0.5$

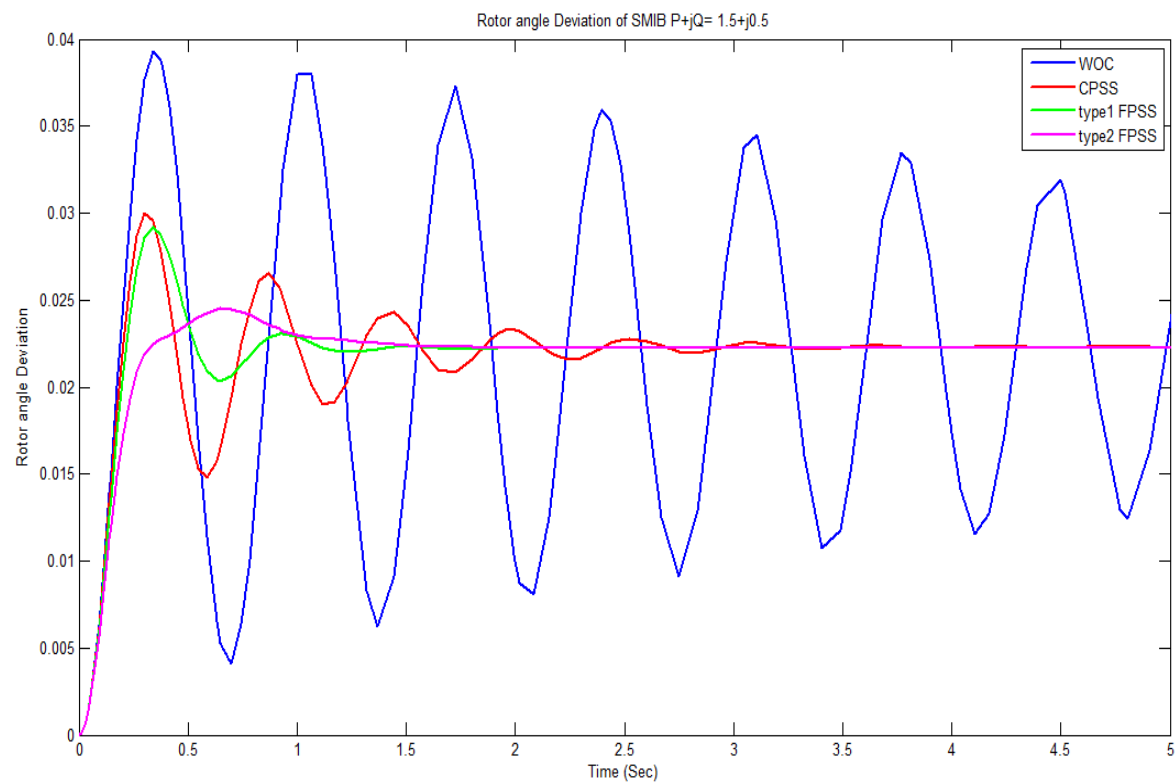

Figure 9 Rotor angle deviation at $\mathrm{P}+\mathrm{jQ}=1.5+\mathrm{j} 0.5$ 
Table 2 shows the settling time, peak overshoot and peak undershoot in frequency deviation with different controllers under wide operating conditions. From the table it is observed that type- 2 FLPSS makes the speed deviation to Settles faster with lower peak overshoot and undershoot compared to type-1 FLPSS and CPSS.

Table 2: Speed deviation of SMIB for different operating conditions

\begin{tabular}{|c|c|c|c|c|}
\hline $\begin{array}{c}\text { Response } \\
\text { Characteristics } \\
\end{array}$ & $\begin{array}{c}\text { Response } \\
\text { Characteristics } \\
\end{array}$ & CPSS & Type1 FPSS & Type2 FPSS \\
\hline \multirow{3}{*}{$0.5+\mathrm{j} 0$} & Settling Time $(\mathrm{Sec})$ & 3.026 & 1.57 & 1.307 \\
\hline & $\begin{array}{l}\text { Peak Overshoot } \\
(\mathrm{rad} / \mathrm{sec})\end{array}$ & $5.021 \times 10^{-4}$ & $4.577 \times 10^{-4}$ & $3.54 \times 10^{-4}$ \\
\hline & $\begin{array}{l}\text { Peak Undershoot } \\
(\mathrm{rad} / \mathrm{sec})\end{array}$ & $-1.806 \times 10^{-4}$ & $-6.998 \times 10^{-5}$ & $-9.357 \times 10^{-8}$ \\
\hline \multirow{3}{*}{$0.7+\mathrm{j} 0.3$} & Settling Time (Sec) & 3.542 & 1.947 & 1.226 \\
\hline & $\begin{array}{l}\text { Peak Overshoot } \\
(\mathrm{rad} / \mathrm{sec})\end{array}$ & $4.688 \times 10^{-4}$ & $4.307 \times 10^{-4}$ & $3.482 \times 10^{-4}$ \\
\hline & $\begin{array}{l}\text { Peak Undershoot } \\
\text { (rad/sec) }\end{array}$ & $-2.383 \times 10^{-4}$ & $-1.363 \times 10^{-4}$ & $-1.356 \times 10^{-5}$ \\
\hline \multirow{3}{*}{$0.7-\mathrm{j} 0.3$} & Settling Time (Sec) & 3.066 & 2.109 & 1.976 \\
\hline & $\begin{array}{l}\text { Peak Overshoot } \\
(\mathrm{rad} / \mathrm{sec})\end{array}$ & $4.7 \times 10^{-4}$ & $4.153 \times 10^{-4}$ & $3.132 \times 10^{-4}$ \\
\hline & $\begin{array}{l}\text { Peak Undershoot } \\
\text { (rad/sec) }\end{array}$ & $-1.752 \times 10^{-4}$ & $-3.167 \times 10^{-5}$ & ----- \\
\hline \multirow{3}{*}{$1+\mathrm{j} 0$} & Settling Time (Sec) & 3.06 & 1.756 & 1.616 \\
\hline & $\begin{array}{l}\text { Peak Overshoot } \\
(\mathrm{rad} / \mathrm{sec})\end{array}$ & $4.477 \times 10^{-4}$ & $3.99 \times 10^{-4}$ & $3.199 \times 10^{-4}$ \\
\hline & $\begin{array}{l}\text { Peak Undershoot } \\
(\mathrm{rad} / \mathrm{sec})\end{array}$ & $-1.926 \times 10^{-4}$ & $-6.523 \times 10^{-5}$ & $-2.727 \times 10^{-6}$ \\
\hline \multirow{3}{*}{$1.5+\mathrm{j} 0.5$} & Settling Time (Sec) & 4.24 & 2.513 & 1.508 \\
\hline & $\begin{array}{l}\text { Peak Overshoot } \\
(\mathrm{rad} / \mathrm{sec})\end{array}$ & $4.084 \times 10^{-4}$ & $3.703 \times 10^{-4}$ & $3.007 \times 10^{-4}$ \\
\hline & $\begin{array}{l}\text { Peak Undershoot } \\
(\mathrm{rad} / \mathrm{sec})\end{array}$ & $-2.333 \times 10^{-4}$ & $-1.218 \times 10^{-4}$ & $-1.659 \times 10^{-5}$ \\
\hline \multirow{3}{*}{$1.5-\mathrm{j} 0.2$} & Settling Time (Sec) & 3.659 & 2.225 & 1.617 \\
\hline & $\begin{array}{l}\text { Peak Overshoot } \\
(\mathrm{rad} / \mathrm{sec})\end{array}$ & $4.533 \times 10^{-4}$ & $4.015 \times 10^{-4}$ & $3.067 \times 10^{-4}$ \\
\hline & $\begin{array}{l}\text { Peak Undershoot } \\
(\mathrm{rad} / \mathrm{sec})\end{array}$ & $-1.802 \times 10^{-4}$ & $-5.185 \times 10^{-5}$ & ---- \\
\hline
\end{tabular}

Table 3 shows the settling time, peak overshoot and peak undershoot in rotor angle deviation with different controllers under wide operating conditions. From the table it is observed that type- 2 FLPSS makes rotor angle deviation Settles faster with lower peak overshoot and undershoot compared to type-1 FLPSS and CPSS. 
International Journal of Fuzzy Logic Systems (IJFLS) Vol.6, No.1, January 2016

Table 3: Rotor Angle deviation of SMIB for different operating conditions

\begin{tabular}{|c|l|c|c|c|}
\hline $\begin{array}{c}\text { Operating } \\
\text { condition }\end{array}$ & \multicolumn{1}{c|}{$\begin{array}{c}\text { Response } \\
\text { Characteristics }\end{array}$} & CPSS & Type1 FPSS & Type2 FPSS \\
\hline \multirow{3}{*}{$0.5+\mathrm{j} 0$} & Settling Time (Sec) & 2.609 & 1.513 & 1.09 \\
\cline { 2 - 5 } & Peak Overshoot (rad) & 0.04747 & 0.04953 & 0.04607 \\
\cline { 2 - 5 } & Peak Undershoot (rad) & 0.03403 & 0.04354 & ---- \\
\hline \multirow{3}{*}{$0.7+\mathrm{j} 0.3$} & Settling Time (Sec) & 3.099 & 1.746 & 1.226 \\
\cline { 2 - 5 } & Peak Overshoot (rad) & 0.0402 & 0.04072 & 0.03427 \\
\cline { 2 - 5 } & Peak Undershoot (rad) & 0.02264 & 0.02894 & ----- \\
\hline \multirow{3}{*}{$0.7-\mathrm{j} 0.3$} & Settling Time (Sec) & 2.844 & 1.976 & 1.848 \\
\cline { 2 - 5 } & Peak Overshoot (rad) & 0.0407 & 0.04248 & ----- \\
\cline { 2 - 5 } & Peak Undershoot (rad) & 0.02925 & 0.04042 & ---- \\
\hline \multirow{3}{*}{$1+\mathrm{j} 0$} & Settling Time (Sec) & 2.942 & 1.832 & 1.566 \\
\cline { 2 - 5 } & Peak Overshoot (rad) & 0.03711 & 0.03739 & 0.03445 \\
\cline { 2 - 5 } & Peak Undershoot (rad) & 0.02434 & 0.03256 & ------ \\
\hline & Settling Time (Sec) & 3.767 & 1.996 & 1.576 \\
\cline { 2 - 5 } & Peak Overshoot (rad) & 0.03 & 0.02918 & 0.0245 \\
\cline { 2 - 5 } & Peak Undershoot (rad) & 0.0148 & 0.02036 & ------ \\
\hline \multirow{2}{*}{$1.5-\mathrm{j} 0.2$} & Settling Time (Sec) & 2.225 & 2.1 & 2 \\
\cline { 2 - 5 } & Peak Overshoot (rad) & 0.03829 & 0.3903 & 0.3571 \\
\hline
\end{tabular}

\section{CONClusions}

In this paper a type-2 FLPSS is implemented to increase the dynamic stability of SMIB system. Different operating points were used to test robustness of the proposed controller. The efficacy in damping of oscillations of proposed controller is compared with type-1 FLPSS and CPSS. Type-2 FLPSS makes the system settle faster compared to type-1 FLPSS and CPSS. Results show that even when operating conditions change, type-2 FLPSS provides good damping and improves system performance.

\section{REFERENCES}

[1] Demello FP, Concordia C.,(1969) "Concepts of synchronous machine stability as affected by excitation control", IEEE Trans Power Apparatus Systems, Vol. 88, No.4, pp316-328.

[2] Larsen EV, Swann DA., (1981) "Applying power system stabilizers part i-iii”, IEEE Trans Power App Syst. Vol. 100, N0.6, pp3017-3046.

[3] Kundur P, Klein M, Rogers GJ, Zywno MS., (1989) "Application of power system stabilizers for enhancement of overall system stability”, IEEE Trans Power Syst., Vol. 4, No. 2, pp614-626.

[4] Klein M, Rogers GJ, Kundur P., (1991) “ A fundamental study of inter-area oscillations in power systems”, IEEE Trans Power Systems, Vol.6, pp914-921.

[5] Kundur P. (1994) Power system stability and control. McGraw-Hill Inc.

[6] Teh-Lu L., (1999) "Design of an adaptive nonlinear controller to improve stabilization of a power system", Elect Power Energy Syst., Vol. 21, pp433-441.

[7] K. Saoudi, M.N. Harmas, (2014) "Enhanced design of an indirect adaptive fuzzy sliding mode power system stabilizer for multi-machine power systems", Electrical Power and Energy Systems, Vol. 54, pp425-431.

[8] Shaw B, Banerjee A, Ghoshal S, Mukherjee V,( 2011) "Comparative seeker and bioinspired fuzzy logic controllers for power system stabilizers". Int J Elec Power Ener Syst., Vol. 33, No.10, pp17281738.

[9] Hassan MAM, Malik OP, Hope GS. (1991) "A fuzzy logic based stabilizer for a synchronous machine", IEEE Trans Energy Convers, Vol. 6, No. 3, pp407-413. 
[10] El-Metwally KA, Malik OP.,( 1995) “Fuzzy logic power system stabilizer', IEEE Proc. generation, transmission and distribution, vol. 142, No.3, pp277-281.

[11] Lakshmi P, Abdullah Khan M., (1998) “ Design of a robust power system stabilizer using fuzzy logic for a multi-machine power system”, Electr. Power Syst. Res, Vol. 47, No. 1, pp39-46.

[12] El-Saady G, El-Sadek MZ, Abo-El-Saud M., (1998) "Fuzzy adaptive model reference approach-based power system static var stabilizer", Electr. Power Syst. Res, Vol. 45, No. 1, pp1-11.

[13] Liang QL, Mendel JM., (2000) "Interval type-2 fuzzy logic systems: theory and design", IEEE Trans Fuzzy Syst, Vol. 8, No. 5, pp535-550.

[14] Mendel JM, John RI, Liu FL.,(2006) "Interval type-2 fuzzy logic systems made simple”, IEEE Trans Fuzzy Syst., Vol. 14, No.6,pp808-21.

[15] Li YM, Du YJ.,( 2012) "Indirect adaptive fuzzy observer and controller design based on interval type2 ts fuzzy model", Appl Math Model, Vol. 36, No.4, pp1558-1569.

[16] K.R. Sudha, R. Vijaya Santhi, (2011) "Robust decentralized load frequency control of interconnected power system with Generation Rate Constraint using Type-2 fuzzy approach", Electrical Power and Energy Systems, Vol. 33, pp699-707.

[17] Sepulveda R, Castillo O, Melin P, Rodriguez-Diaz A, MontielO.,( 2005) "Handling uncertainty in controllers using type-2 fuzzy logic", In: Proceedings of IEEE FUZZ conference, Reno, USA, pp24853.

[18] Vakula.V.S, Sudha K.R,( 2012) "Design of Differential Evolution based Fuzzy Logic Power Sytem Stabilizer with Minimum Rule Base”, IET Gener. Transm. Distrib, Vol. 6, No. 2, pp121-132.

[19] M. A. Awadallah \& H. M. Soliman, (2009) "A Neuro-fuzzy Adaptive Power System Stabilizer Using Genetic Algorithms”, Electric Power Components and Systems, Vol. 37, No. 2, pp158-173.

[20] Adrian Andreiou,( 2002) Genetic Algorithm Based Design of Power System Stabilizers, Dissertation, Chalmers University of Technology.

[21] Lee J.,(1993) "On methods for improving performance of PI-type fuzzy logic controllers", IEEE Trans Fuzzy Systems, Vol. 1, No. 4, pp298-301.

[22] Mendel JM., (2000) Uncertain rule-based fuzzy logic systems: introduction and new directions, Ed. Prentice Hall, USA.

[23] A. Abbadi , L. Nezli and D. Boukhetala,( 2013), "A nonlinear voltage controller based on interval type 2 fuzzy logic control system for multi-machine power systems”, Electrical Power and Energy Systems, vol. 45, pp456-467.

[24] Hidalgo D, Castillo O, Melin P., (2009) “Type-1 and type-2 fuzzy inference systems as integration methods in modular neural networks for multimodal biometry and its optimization with genetic algorithms", J Inform Sci., Vol. 179, No.13, pp2123-45. 